\title{
DEVIATIONS OF FISCHER-TROPSCH PRODUCTS FROM AN ANDERSON-SCHULZ-FLORY DISTRIBUTION
}

\author{
Ruud SNEL \\ University of Twente, Faculty of Chemical Technology P.O. Box 217, 7500 AE Enschede, \\ The Netherlands
}

Submitted 21 July 1988; accepted 6 September 1988

\begin{abstract}
Negative deviations from an Anderson-Schulz-Flory distribution have been observed for the product of the Fischer-Tropsch synthesis. The catalyst was a complex-derived iron-calcium catalyst promoted with cesium sulphate, therefore, neither carrier acidity nor shape selectivity can explain the deviations. This is the first time that chemical modifications of the catalyst are observed to result in negative ASF deviations.
\end{abstract}

\section{Introduction}

Almost invariably it is possible to describe the product distribution of the Fischer-Tropsch synthesis by Anderson-Schulz-Flory (ASF) statistics [1], which can be mathematically expressed as:

$\Phi_{n}=\Phi_{i} P^{n-i}$

where $\Phi_{n}$ and $\Phi_{i}$ are the number of moles of a hydrocarbon with carbon number $n$ or $i$ respectively and $P$ is the probability of chain growth. For any given value of $P$ the product spectrum is fixed. Because of the general applicability of ASF statistics, selective synthesis remains a challenge [2].

It has recently been shown that the value of $P$ is not necessarily independent of chain length and that in some cases an increased value is observed in the higher molecular mass region above about $\mathrm{C}_{10}-\mathrm{C}_{13}$ [3]. The positive deviation has been attributed to a dual site synthesis mechanism. Negative deviations are also known, but are of external origin. When an acidic carrier [4,5] is used, the size of the higher product is limited by selective hydrogenolysis, or in addition by shape selectivity in the case of zeolites [6]. Moreover, transient holdup of higher molecular mass products in liquid phase operation is also known to cause negative deviations [7]. In this communication we report on the first chemically induced negative deviation. 


\section{Catalytic materials and experimental procedures}

Highly disperse carbon-containing metals derived by partial degradation of $\mathrm{Fe}$ complexes are a new class of catalyst for the selective hydrogenation of $\mathrm{CO}$ to alkenes [8]. Amorphous mixed-metal complexes are obtained from solutions containing metal salts and polyfunctional hydroxyacids. Using this concept several different iron citrate complexes containing other metals at different concentrations have been prepared. Partial combustion of the complexes yielded a variety of materials with the general formula $\mathrm{Fe}_{x} \mathrm{M}_{y} \mathrm{O}_{z} \mathrm{C}_{a}$, in which $\mathrm{M}$ represents one or more different metal(s). Scanning Auger electron microscopy revealed that in the outermost surface layer of these materials the value for $a$ is in general ca 0.5 and decreases to approach zero at the fourth atomic sub-surface layer.

In this work a promoted iron-calcium catalyst was used. The iron-calcium (atomic ratio $\mathrm{Fe}: \mathrm{Ca}=1$ ) prepared from the mixed citrate complex. After partial degradation of the complex, $\mathrm{Cs}_{2} \mathrm{SO}_{4}$ was introduced by incipient wetness impregnation to an atomic ratio $\mathrm{Fe}: \mathrm{Cs}=33$.

Catalytic reaction experiments were carried out with the reduced material in a fixed-bed microreactor system with on-line gas chromatographic analysis of the products, described elsewhere [9-12]. The reaction conditions were $2.0 \mathrm{MPa}$ and $543 \mathrm{~K}$. Synthesis gas with a $\mathrm{H}_{2} / \mathrm{CO}$ ratio $=0.5$ was passed at a space velocity $\mathrm{VHSV}=1000$.

\section{Results and discussion}

The non-promoted version of the catalyst had a product which adhered to ASF statistics, the value of $P$ being 0.63 . The product distribution obtained with the promoted catalyst has a negative deviation from normal ASF behaviour for the $\mathrm{C}_{7+}$ hydrocarbon fraction (fig. 1). The value of $P$ was identical for the $\mathrm{C}_{1}-\mathrm{C}_{6}$ hydrocarbon fraction obtained with both catalysts. While the unpromoted catalyst gave a $C_{7+}$ hydrocarbon product with the same value for $P$, a much lesser value was obtained for this fraction with the promoted catalyst. It is suggested that chemical modification of the catalyst has resulted in a modified synthesis mechanism that limits the synthesis of higher hydrocarbons without affecting the synthesis of light products.

It should be stressed that this result was not obtained only in the initial stages using a fresh catalyst or at very low conversion levels where deviations are known to be possible [2]. The data depicted in fig. 1 were obtained with a catalyst which was already five days on stream, working at steady state at a conversion level of ca $40 \%$. Furthermore, the phenomenon was found to be reproducible; very little difference was observed between the results of three different experiments. Moreover, the overall carbon material balances were in all cases in the range 


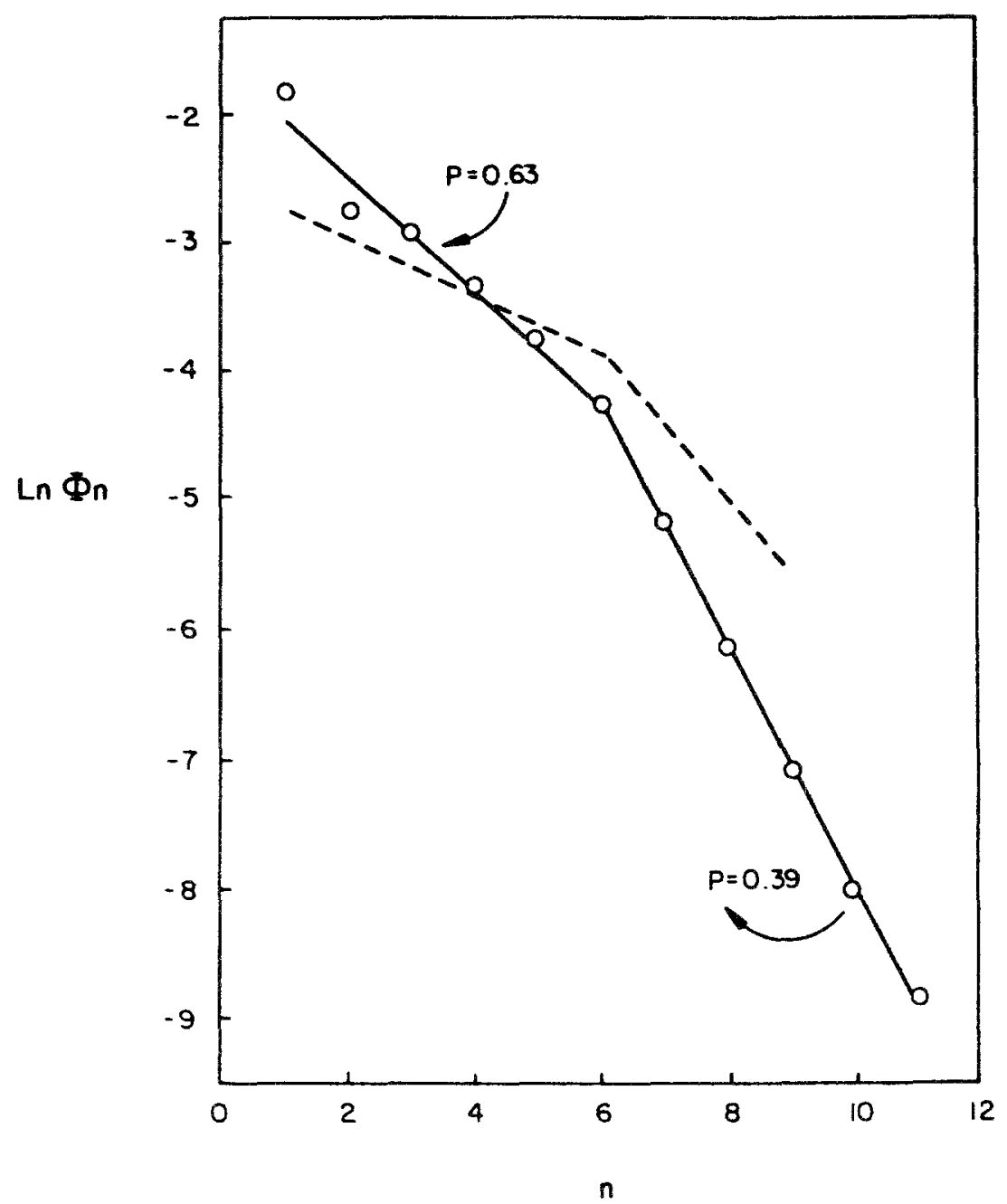

Fig. 1. Typical ASF plot obtained after 5 days on stream. The dotted line represents data reported with $\mathrm{Fe} / \mathrm{ZSM} 5$ [6].

$98-102 \%$, definitely demonstrating that a real 'non-ASF' distribution was being observed.

The product spectrum is similar to that obtained with zeolite supported iron catalysts [6]. While shape selectivity and selective hydrogenolysis are explanatory for the behaviour of the acidic system, such reasons cannot apply in the present case. A possible explanation could involve a dual site mechanism where one specific site type is selectively poisoned by the sulphate. This explanation could be supported by the observation that the molecular structure of the products was mainly linear. However, further studies are needed for a deeper understanding of the mechanistic aspects. We are at present engaged in such studies. 


\section{Acknowledgements}

This work was carried out in the Catalysis Division of the National Institute of Chemical Engineering, CSIR in Pretoria, South Africa, which has recently ceased to exist. The author thanks the former chief director for permission to publish this work.

\section{References}

[1] R.B. Anderson, J. Catal. 55 (1978) 14.

[2] R. Snel, Catal. Rev. -Sci. Eng. 29(4) (1987) 361.

[3] N.O. Egiebor, W.C. Cooper and B.W. Wojciechowski, Can. J. Chem. Eng. 63 (1985) 826.

[4] J. Barrault and C. Renard, Nouv. J. Chim. 7(3) (1983) 149.

[5] M. van der Riet, R.G. Copperthwaite and G.J. Hutchings, J. Chem. Soc., Chem. Commun. (1986) 798.

[6] T. Mitsudo, H. Boku, S. Murachi, A. Ishihara and Y. Watanabe, Chem. Lett. (1985) 1463.

[7] R.A. Dictor and A.T. Bell, Ind. Eng. Chem. Process Des. Dev. 22 (1983) 681.

[8] R. Snel, Prepr. Div. of Petrol. Chem., Am. Chem. Soc. 30(4) (1985) 723.

[9] R. Snel, Chem. Scr. 20 (1982) 99.

[10] R. Snel, Ind. Eng. Chem. Fundam. 24 (1985) 257.

[11] R. Snel, 2nd Int. Symp. Anal. Chem. Explor. Minerals and Materials, Pretoria, 15-19 April 1985. (Available as CSIR report CENG 546).

[12] R. Snel, Chromatographia 5 (1986) 265. 